\title{
Spatio-temporal variability of daily precipitation concentration in Spain based on a high-resolution gridded dataset
}

\author{
R Serrano-Notivoli ${ }^{\mathrm{a}, \mathrm{b}}$, J Martín-Videc, M A Saz ${ }^{\mathrm{b}}$, L A Longares ${ }^{\mathrm{b}}$, S Beguería ${ }^{\mathrm{d}}$, P \\ Sarricolea $^{c, e}$, O Meseguer-Ruiz ${ }^{c, f}$ and $M$ de Luis ${ }^{b}$ \\ ${ }^{a}$ Barcelona Supercomputing Center (BSC), Spain \\ ${ }^{\mathrm{b}}$ Dept. of Geography and Regional Planning, University of Zaragoza, Spain. \\ ${ }^{\mathrm{c}}$ Climatology Group, University of Barcelona, Spain. \\ ${ }^{\mathrm{d}}$ Estación Experimental de Aula Dei (EEAD-CSIC), Zaragoza, Spain. \\ ${ }^{\mathrm{e}}$ Dept. of Geography, University of Chile, Chile. \\ ${ }^{\text {f }}$ Departamento de Ciencias Históricas y Geográficas, Universidad de Tarapacá, Chile.
}

\begin{abstract}
An analysis of the spatial and temporal variability of daily precipitation concentration (CI) in Spain was made based on a high-resolution (5x5 km) daily gridded precipitation dataset for the 1950-2012 period. For each grid point in the Iberian Peninsula (IP), and Balearic and Canary Islands, the average annual CI was computed, as well as its coefficient of variation and the $5^{\text {th }}$ and $95^{\text {th }}$ percentiles. Annual values were also computed, and the time series of the index were used to assess temporal trends over the whole period. The spatial distribution of the CI showed a strong relationship with the orographic barriers near the coastlines. The Canary Islands showed the highest values of CI, along with the eastern Mediterranean facade of the IP. The highest inter-annual variations of the CI occurred in the southern IP and in the southern Canary Islands. The trends of CI were, overall, positive and significant, which indicates an increase of daily precipitation concentration over the study period, and an increasing environmental risks scenario where erosivity, torrentiality, and floods may become more frequent.
\end{abstract}

Keywords: Precipitation, Spain, extreme event, spatial analysis, trends, Concentration Index.

Short title: Variability of daily precipitation concentration in Spain

*Correspondence to: Roberto Serrano-Notivoli.rs@@unizar.es. +31876554029

This is the pre-peer reviewed version of the following article [Serrano-Notivoli, R., Martín-Vide, J., Saz, M. A., Longares, L. A., Beguería, S. , Sarricolea, P. , Meseguer-Ruiz, O. and de Luis, M. (2018), Spatio-temporal variability of daily precipitation concentration in Spain based on a high-resolution gridded data set. Int. J. Climatol, 38: e518-e530. doi:10.1002/ joc.5387], which has been published in final form at https://rmets.onlinelibrary.wiley.com/doi/pdf/10.1002/joc.5387. This article may be used for non-commercial purposes in accordance with Wiley Terms and Conditions for Use of Self-Archived Versions 


\section{Introduction}

The precipitation concentration is an important parameter of the climatic description of a single location or region, which complements and qualifies the information provided by other, more common, variables such as the annual precipitation or the seasonality. Precipitation concentration is also useful for exploring the risks related to extreme precipitation events. The CI index (MartinVide, 2004) is one of the few indices that are able to relate the magnitude of the precipitation events to the time period in which they occur. It has clear climatic and environmental applications due to its crucial role for water resources by determining the water availability during a drought period, or by forecasting the high intensity events that can lead to floods or geomorphological risks. In this sense, the $\mathrm{CI}$ is useful in erosion studies due to the ability of the index to act as an estimator of rainfall erosivity (De Luis et al., 2010a). The relationship between the concentration and the precipitation intensity allows, along with the spatial resolution of the analysis, the furthering of the understanding of rainfall intensity at the local scale. Furthermore, the precipitation concentration is remarkably useful in the context of climate change, because it is able to assess the repercussions of a water cycle enforcing due to an increase in evapotranspiration (Vicente-Serrano et al., 2014, 2016), especially the high-intensity precipitation.

In spite of its capabilities, the use of the CI index is restricted due to the requirement of daily precipitation data. High-resolution daily precipitation datasets are not as common as monthly or annual-scale ones (Huffman et al., 1997, Haylock et al., 2008; González-Hidalgo et al., 2011; Harris et al., 2014). The existing daily datasets comprise a limited number of observatories, and the extrapolation of their information to a wider territory is a complex task that can lead to nontrivial uncertainties. In addition, the CI index was originally conceived as a static indicator to characterise pluviometric regimes over a reference period. This static character prevents the assessment of variability, extremes, or temporal trends.

The CI was tested for the first time in Spain using daily observations from 32 locations (MartínVide, 2004). Since then, the high-resolution daily precipitation gridded dataset SPREAD has been 
created, including 20,882 daily resolved locations for the period 1950-2012 (Serrano-Notivoli et al., 2017a).

The objective of this research is to assess the spatial and temporal variability of daily precipitation concentration in Spain (including the Balearic and Canary Islands) through the new SPREAD dataset. The possibility of the CI calculation at an annual time-scale is tested to complete a wider description of its behaviour through the computing of: a) its mean value (presumably similar to the CI calculation using the whole series); b) its inter-annual variability (through the coefficient of variation); c) the extreme values that the index is able to reach in different parts of the territory; and d) the trends of the index in the 1950-2012 period. The general objective is to identify, for first time in an especially vulnerable territory (such as the Spanish Iberian Peninsula, and the Balearic and the Canary Islands), the spatial and temporal distribution patterns of the daily precipitation concentration. To do this, these patterns are described from a climatic point of view, looking for causes, and contributing to the creation of results particularly relevant for land management. The paper is organised as follows: Section 2 describes the data, the study area, and the methodology. The results are detailed in Section 3, describing the spatial and temporal distribution of the index, its variability and trends. These results are then discussed in Section 4, with a short summary of the main results in Section 5.

\section{Methods}

\subsection{Data and study area}

The dataset used was the $5 \times 5$ km SPREAD gridded dataset (Serrano-Notivoli et al., 2017a), which contains daily precipitation estimations covering the Spanish Iberian Peninsula, and the Balearic and Canary Islands (Figure $1 \mathrm{a}$ ). This dataset was built using a total of 12,858 precipitation stations with original observations (Figure 1 b) obtained from the Spanish Meteorological Agency (AEMET) and other regional meteorological agencies, covering the period 1950-2012. The original series of observations were completely reconstructed using the $\mathrm{R}$ package reddPrec (Serrano-Notivoli et al., 2017b), following the methodology described in Serrano-Notivoli et al. 
(2017c), which is based on three stages: i) the application of a comprehensive quality control to detect and remove suspect data (suspect zeros and data, suspect outliers, and suspect wet and dry days); ii) the estimation of daily precipitation for all observatories with missing values in all days for the whole cleaned dataset, based on the nearest observations; and iii) after the completion of all the original series, the grid was built for all the Spanish territory and the entire period of the reconstructed stations by estimating, at each grid point, the daily precipitation based on the nearest reconstructed stations.

The aim of the gridded datasets is to be representative of a territory along with the minimum differences between grid areas and point-based observations. These differences can be reduced in a large fraction by i) increasing the density of the stations network and the spatial resolution of the grid, ii) the local adaptive estimation of daily precipitation values for each grid point. SPREAD fulfils both premises by using i) all daily precipitation data available for the study area and ii) producing time series for each grid point that reproduce the structural characteristics of neighbor observations in terms of their totals but also in the frequency of dry/wet days and extreme precipitation magnitudes (Serrano-Notivoli et al., 2017a, 2017c).

The precipitation in Spain has a large range of values, with annual averages from less than 100 $\mathrm{mm}$ to close to $3,000 \mathrm{~mm}$, and complex spatial patterns. This is due to the influence of the very contrasting geographical factors, such as altitudes that reach more than 3,000 m a.s.l., the Atlantic Ocean to the West, the Mediterranean Sea to the East, and the fact that northern part of the contiguous Spain is the border between the mid-latitude maritime climate and the Mediterranean climate.

The average annual precipitation (Figure $1 \mathrm{c}$ ) shows a rainy northern fringe, with more than 800 mm (the 'rainy Iberia'), and modest or low values in the rest of the Spanish Iberian Peninsula (the 'dry Iberia'). The driest area is the southeast, with less than $300 \mathrm{~mm}$ (the 'semi-arid Iberia'). The southeast extreme is considered to be the driest place in continental Europe, with $150 \mathrm{~mm}$. Some of the main ranges in the dry Iberia have annual averages similar to the ones of the rainy Iberia. Along a diagonal from the extreme southeast to some places in the northwest, the annual mean 
precipitation is multiplied by 20 times. The Balearic Islands have an annual precipitation that corresponds to the same latitudes in the Iberian Peninsula. Meanwhile, the Canary Islands are, in general terms, dry or very dry, with values that do not reach $100 \mathrm{~mm}$ in the south of the eastern islands.

The mean annual number of rainy days (Figure $1 \mathrm{~d}$ ) shows a quite similar spatial pattern to the average annual precipitation, with increasing values from the southeast to the northwest.

\subsection{Precipitation concentration index}

The CI uses daily precipitation amounts over a long period, but it can be also calculated for one year, as shown in this paper. The first step for the calculation of CI is to arrange the daily precipitation values in ascending order. Then the cumulative percentage of rainy days is plotted against the corresponding cumulative percentage of rainfall amounts, and has a markedly exponential shape. These curves are of the kind:

$$
Y=a X \exp (b X)
$$

where $a$ and $b$ are constants. They can be calculated by means of the least-squares method.

The definite integral of the exponential curve between 0 and 100 is the area, $A$, under the curve, and 5,000-A is the area compressed by the curve, $Y=X$, and $X=100$, lets name $S$. Then CI is defined as:

$$
C I=S / 5,000
$$

The CI measures the relative separation of the exponential curve from the $Y=X$ line. Note that the separation is greater (or CI is higher), when the weight of a few days, the rainiest ones, in the total is higher (Martin-Vide, 2004; Cortesi et al., 2012; Benhamrouche et al., 2015). The CI is similar to the well-known Gini index.

Figure 2 shows the exponential curves of two contrasting locations in the 1950-2012 period. La Coruña (Figure 2 a) is located in the northwest Iberian Peninsula, a rainy region, where the daily amounts are quite similar. Valencia (Figure $2 \mathrm{~b}$ ) is located in the eastern IP, where some torrential 
rainfalls occur almost every year. In this region, a few rainy days accumulate most of the total annual precipitation. The differences in the annual exponential curves in each location help in understanding the precipitation regimes.

The CI index was calculated for all the 20,242 points of the grid by using the R package precintcon (Venezian and Teixeira, 2016) for the three geographical units (IP, Balearic Islands, and Canary Islands). The CI was applied, as originally described (Martín-Vide, 2004), to the complete series (CIc) from 1950 to 2012 in each grid point. Additionally, the CI was computed at each grid point individually for each year to complete a wider description of the precipitation concentration in Spain. We calculated both versions (complete and annual series) to make a comparison of conventional works (complete series) and this new and comprehensive approach (annual series). Then, the average (CIm), the coefficient of variation (CIcv), and the $5^{\text {th }}$ and $95^{\text {th }}$ percentiles (CIp05 and CIp95, respectively) of the annual CI values for each grid point were calculated as a set of descriptors of centrality, variability, and extreme characterisation of precipitation concentration across the study area.

Finally, a trend analysis was also performed to evaluate the temporal evolution of the CI in Spain throughout the 1950-2012 period. The magnitude of trends was estimated using the Sen's slope (Sen, 1968) and represented as a percentage of change with respect to the decadal CI mean in the 1950-2012 period. Significance of trends was calculated using the Mann-Kendall test (Mann, 1945; Kendall, 1948), considering trends as significant when $p$-value $<0.05$. The obtained indices and trends were mapped to examine the spatial distribution of the CI means, variability, extreme values, and trends.

\section{Results}

\subsection{Spatial distribution of CI across Spain}

The spatial distribution of CI computed with complete series (CIc) (Figure 3 a) is similar to that obtained by averaging the annual CI indices (CIm) (Figure $3 \mathrm{~b}$ ). Overall, the values of CIm are slightly lower in magnitude and variability than those of CIc (Figure 4 a). Despite the differences 
found between the two methods of calculation, a common spatial pattern of CI in the IP was found (Figure 4 b).

The highest values are distributed in the Canary Islands and in a latitudinal band in the east of IP, coinciding with the Mediterranean fringe, that gains access in the Ebro Valley and the Pyrenees. $\mathrm{CI}$ is also relatively high, overall, in elevated areas and in the Cantabrian Range, while the Southern Plateau and the continental northwest IP had the lowest values. Altogether, the coastlines show higher values than the inner areas. The global distribution shows that highest CI values are along the coast with mountain ranges that are parallel to them. In those areas where this mountain ranges are disrupted (i.e. the Ebro or Guadalquivir valleys), the CI progresses inland. The Central Range, perpendicularly orientated to the Atlantic coast, represents the exception, with high CI values that are explained by the absence of high mountain barriers in the western IP.

\subsection{Temporal variability of CI across Spain}

The spatial distribution of the coefficient of variation of annual CI (CIcv) (Figure 5), shows different patterns than those observed for CIc and CIm (Figure 3). The highest values are observed in the southern IP and in the southern part of the Canary Islands. The CIcv shows also higher values in the southern half of the Mediterranean coast, coinciding with the area with the least total precipitation in peninsular Spain (Figure $1 \mathrm{c}$ ), as well as the southern side of the Canary Islands. Overall, the spatial pattern shows a clear northwest-southeast gradient. The south-eastern IP shows a high variability and high averaged precipitation concentrations, while the Ebro Valley and the Pyrenees show high values of CI but lower variability. The Northern Plateau and the Cantabric coast reach the lowest variability in Spain and very high values of CI, and the southwest IP shows regular values of average precipitation concentrations with high variability.

The Mediterranean coast, the Ebro Valley, and the Cantabric coast always show higher precipitation concentrations (CIp05 is always over 0.5) than the rest of the IP (Figure 6). In contrast, the southern half of the IP shows the lowest CI values, even reaching under 0.4 in a large 
part of the territory. On the other hand, the extreme values of concentration occur in the Mediterranean sector, where in some years the CI values exceed 0.75 . These high values (over 0.7) are also reached in the interior of the Ebro Valley, and in highest elevations of the eastern Pyrenees. On the contrary, the maximum values of concentration exceeding 0.6 are rare and only occur in flat areas of Northern and Southern Plateaus, and in the interior of northwest IP.

The spatial and temporal variability of precipitation concentration across Spain can be divided into four geographical regions:

i) the Mediterranean coast reaches the highest values of the index, shows a high interannual variability, and has extreme values that exceed 0.75 in some years;

ii) the southwestern IP has moderately low values of the index, but the area is highly variable between years. The precipitation concentration can be very low some years $(\mathrm{CI}<0.4)$, and very high $(\mathrm{CI}>0.7)$ in others;

iii) the northern sector, comprising the Pyrenees, the Ebro Valley, and especially the Cantabric coast, has CI values close to the average with low inter-annual variability. The precipitation concentration usually ranges between 0.5 and 0.7 ;

iv) the Northern and Southern Plateaus have the lowest mean precipitation concentration and a low variability, which means that the CI values differ over a short range from a minimum of around 0.55 to a maximum not greater than 0.65 .

\subsection{Spatial distribution of CI trends}

CI trends over the 1950-2012 period indicate a global increase in precipitation concentration in Spain (Table 1), with most of the territory in the IP showing a positive significant trend (57.3\%), as well as in the Balearic Islands (50.2\%). Negative and significant trends in these two areas are minimal (3.8 and 0.5\%, respectively). The Canary Islands show mostly non-significant trends (81.5\%), dominating positive trends in significant areas (14.2\%).

The spatial distribution in the IP shows a global SW-NE trend, especially in the areas corresponding to the Central Range, the east and west sides of the Guadalquivir Valley, and the 
southwest part of the IP, where the maximum positive values are concentrated (Figure 7). The northern half of the IP has a concentration of more negative trends, but the magnitudes of the values are lower than the positive ones. Most of the territory in the Balearic Islands shows positive significant trends, while the spatial pattern in the Canary Islands is different. The eastern islands show non-significant trends over most of their area, while negative trends prevail in the western islands.

The Mediterranean coast (including the Balearic Islands) is dominated by positive trends, which are especially intense (>4\%/decade) in the areas coinciding with higher inter-annual variability. However, the central (high concentration and low variability) and southern (mid concentration and high variability) sectors do not show significant trends in general. The southwestern area of the IP shows the highest positive trend values, from the south coast to the Central Range, where the trends are intense mainly on its western side. All of this area is dominated by large interannual variability of precipitation concentration, reaching the lowest $\mathrm{CI}$ in some years. The regions of the northern sector are very different from each other. For instance, the Pyrenees show high positive trend values except in the central sector, just like the Ebro Valley, that shows only a few areas with significant trends, most of them with negative values. The Cantabric coast shows mean values of positive trends (between $1 \%$ and 3\%) except in the central sector with nonsignificant trends, or small areas with negative values. Finally, the Northern and Southern Plateaus show a different range of trend values. The first one is dominated by mid-low positive trends with wide extents of non-significant trends, and the southern one, with more variability, shows the highest values of positive trends, exceeding $4 \%$ in its central sector.

There is a clear connection between the CI variability and the intensity of the trends. Those areas with a high inter-annual variability (CIcv) and with the lowest values of annual CI (CIp05), are prone to change towards a more intense precipitation concentration (Figure 8). Although not all of Spain fulfils this statement (the southwestern extreme of the IP and the southern Canary Islands, for instance, have high variability but non-significant trends), the premise is valid for almost all the territory. 


\section{Discussion}

The CI is a proper index which can be used to describe the daily concentration of precipitation. Furthermore, its annual calculation allows the evaluation of the daily concentration distribution from a dynamic point of view by including the analysis of its variability, extremes, and trends. Within this context, Spain is a territory where the precipitation dynamics represent a key environmental factor from different perspectives (economic, ecological risks, etc.). Many studies have characterised the precipitation regime, distributions, and means, but most of them were based on descriptors or indices computed at a monthly or annual scale (Esteban-Parra et al., 1998; Rodríguez-Puebla, 1998; González-Hidalgo et al., 2011; Cortesi et al., 2014). Still, the changes in Spanish precipitation over the most recent decades have been thoroughly analysed through the study of trends, showing, overall, a shortening of the wet season, an increase of precipitation in October, a decrease in March (González-Hidalgo et al., 2011), and a general reduction of precipitation amounts from winter to summer (De Luis et al., 2010b). Also, the concentration of precipitation was analysed through the Precipitation Concentration Index (PCI) at the monthly scale (De Luis et al., 2011, period 1946-2005), showing increases in the central Pyrenees and Ebro basin, the interior of central Mediterranean fringe, and in the southwestern IP. However, precipitation trends present a great uncertainty due to the use of different datasets, periods and regions (Bladé and Castro-Díez, 2010).

This uncertainly is exacerbated when analysing trends in precipitation indices (as CI) that needs a daily resolution for its calculation. The existing daily datasets comprise a limited number of complete observatories, and the extrapolation of their information to a wider territory is a complex task that can lead to non-trivial uncertainties (Martin-Vide, 2004). Moreover, available daily precipitation gridded datasets are rare in comparison with others available for precipitation totals calculated at monthly, seasonal or annual resolution making difficult to stablish comparisons and evaluate the uncertainty of CI trends. 
In this respect, only two additional daily precipitation gridded datasets are available for Spain (SPAIN02: Herrera et al., 2016; SAFRAN: Quintana-Seguí et al., 2017) and both of them are based on a quite different conception in their construction when compared with SPREAD (Serrano-Notivoli et al., 2017a). While both SPAIN02 as SAFRAN are able to reproduce successfully different mean characteristics of precipitation across Spain, both products overestimate the number of precipitation days and underestimate the magnitude of high precipitation events (Quintana-Seguí et al., 2017). Interpolation methods as applied to construct both SPAIN02 as SAFRAN demonstrate to be useful and suitable to validate regional climate models in terms of means and variability but induces several bias in describing the structural characteristics of daily precipitation in relation on its concentration.

SPREAD, by contrast, was specifically designed to reproduce for each grid point the structural characteristics of nearest observations in terms of their totals but also in the frequency of dry/wet days and extreme precipitation magnitudes (Serrano-Notivoli et al., 2017a, 2017c). The potential of SPREAD to be compared or to validate regional climate models needs still to be tested. However, given its close reproduction of the observational precipitation values in terms of frequency of dry/wet days and extreme precipitation magnitudes, SPREAD and the methodology used for its construction represent a new suitable approach to evaluate the evolution of the precipitation concentration as described by the CI (Martin-Vide, 2004).

Thus, this work represents the first attempt to describe comprehensively the dynamic characteristics of daily concentration of precipitation, contributing to the understanding of this process and building upon the previous works focusing on CI in Spain (Martín-Vide, 2004; Cortesi et al., 2014; Máyer and Marzol, 2014; Meseguer-Ruiz et al., 2014). The annual approach, used to analyse variability and trends, has been previously used in some other areas in the world (e.g. Italy: Coscarelli and Caloiero, 2012; New Zealand: Caloiero, 2014; China: Shi et al., 2015). However, this is the first time that the CI has been applied to a complex territory such as Spain, where the risks related to the changes in precipitation concentration are especially relevant. Although a direct comparison with previous stations-based works is not able due to the mismatch 
of the locations of the observatories and SPREAD grid points, the observed CI values for these ones are similar in precipitation concentration magnitude to those described in previous research in IP using observational stations (de Luis et al., 1996; Martin-Vide, 2004), which confirms the feasibility of this dataset for the study of daily precipitation indices.

The study of the distribution patterns of precipitation concentration in Spain allows general areas with different behaviours to be identified. In each one of these areas the concentration is caused by different atmospheric dynamics and has different consequences for environmental risks:

i) The Mediterranean coast shows a very high mean concentration and a high inter-annual variability (especially in the southern IP). In some years the maximum values can exceed 0.75 , with values under 0.5 being infrequent. The overall trend is positive, which indicates an increase in concentration and, consequently, an increase in associated risks. This pattern has already been described in Martín-Vide (2004). The eastern area of the IP is strongly influenced by the Mediterranean atmospheric dynamics (Martín-Vide and López-Bustins, 2006) with frequent convective processes that represent most of the annual precipitation (Álvarez et al., 2011). The presence of unstable, wet and warm air masses produced by a warmer sea, especially at the end of the summer, are responsible of most of these situations. The orographic barriers parallel to the coastline emphasise the importance of these Mediterranean-based events and prevent the arrival of Atlantic fronts, producing a lower number of precipitation days (especially in winter and spring). As a consequence of these premises, the Mediterranean coast is configured as an area where torrentiality is a key environmental risk factor, which may lead to an increase of erosivity or floods processes if current positive trends of concentration continue.

ii) The southwestern IP has low to moderate CI and high inter-annual variability. The trends in this area are positive and strong, showing a clear SW-NE pattern, as well as the CI distribution, following the direction of the Guadalquivir River. The annual precipitation in this area is characterised by its irregularity, mainly due to the complex relief of this part of the IP, but also to its position between two continents and water bodies of contrasting characteristics (García-Barrón et al., 2011). The wet Atlantic fronts penetrating into the Guadalquivir Valley produce the high 
CI values at the elevated areas of its right margin. Martín-Vide (2004) showed in this area a very different and smoothed W-E pattern from highest (0.6) to lowest (0.56) values, probably due to the lack of information in elevated areas. Although the precipitation concentration does not reach very high values, the trends indicate that it has been increasing since the second half of the $20^{\text {th }}$ Century. If this temporal pattern continues, the Guadalquivir Basin could see an increase in the frequency of floods caused by extreme events.

iii) The Ebro Valley and Pyrenees comprise the transition sector from the Mediterranean fringe to the Atlantic influence. The absence of inner mountain barriers allows the Mediterranean precipitation to penetrate to the continental area, while the convective and torrential Mediterranean influence contributes to high CI values with a lower variability due to the influence of the Atlantic fronts and cut-off lows in winter. However, the maximum and minimum values of CI are already high (while they are lower than in the Mediterranean) and the trends are also positive, albeit with slightly lower magnitudes. The spatial patterns in this area were not so clearly described in Martín-Vide (2004). The main consequences of the precipitation concentration in this northern sector are the risks related to a water-scarcity scenario, and soil erosivity in farming areas in the Ebro Valley. Additionally, recurrent flood events in the Pyrenees are a frequent type of risk that are usually due to high amounts of precipitation over a few days (or hours) draining into lower sectors of the Ebro Valley and producing extraordinary socioeconomic losses every year.

The Cantabric coast shows high values of CI with a lower variability, which contributes to more predictable extremes. The trends are overall positive but moderate, which indicates a slower increase of concentration, coinciding with a high regularity of precipitation throughout the year. Again, the orographic effect of the Cantabric range produces high concentrations of precipitation near to the coast by blocking the Atlantic fronts. Floods and erosivity in headwaters of the hydrographic basins are the major risks here.

iv) The Northern and Southern Plateaus, located in the interior of the IP, show similar behaviour to each other. However, the former shows a lower variability and significant trends. Both areas 
are flat and elevated sectors (average 700 and 500 m.a.s.l., respectively) flanked by mountain barriers that separate them from the coast, stalling the progress of high precipitation events. They are isolated by the Central Range, which holds the highest precipitation intensities in Spain (Serrano-Notivoli et al., 2017a). This context contributes to low and regular inter-annual precipitation amounts with a lower frequency of extreme events, resulting in low concentration values and, therefore, a lower level of risk.

In addition to these four global sectors, the Balearic and Canary Islands show different behaviour. The former reach average moderate values of concentration, being higher in the southern islands and high elevations on the central island, where the maximum values and positive significant trends are intensified. This area is completely included in the Mediterranean atmospheric dynamics, and extreme events are very frequent. This is an overpopulated area because of tourism, and most of the flooding risks are focused in urban areas. The precipitation regime in the Canary Islands is highly irregular, encouraging high concentrations, maximum values, and variability, especially on the southern side of the islands where the total amounts are lower. The trends do not indicate a clear pattern, which may be due to this extremely high irregularity, with less than 30 precipitation days per year (Serrano-Notivoli et al., 2017a). Overall, there is no link between the spatial distribution of trends and the climate types. Trends values are spatially distributed in very different precipitation regimes and they are better explained based on geographical factors. The CI values in Spain vary over a small range between 0.50 and 0.70 , with the minimum being slightly higher (0.55) in previous studies in Peninsular Spain (Martín-Vide, 2004; Behamrouche and Martín-Vide, 2012; Meseguer-Ruiz et al., 2014) probably due to the use of a low number of stations $(<32)$, which were not representative of all of the precipitation regimes in the IP. These precipitation concentration values are similar to the rest of Europe (0.51-0.72) (Cortesi et al., 2012), Italy (0.43-0.63) (Coscarelli and Caloiero, 2012), and other regions in the world such as Algeria (0.47-0.70) (Benhamrouche et al., 2015) and New Zealand (0.47-0.70) (Caloiero, 2014). However, it is higher than Malaysia (0.42-0.58) (Suhaila and Jemain, 2012) and Peru (0.44-0.56) (Zubieta et al., 2016); lower than Iran (0.59-0.73) (Alijani et al., 2008) and Chile (0.52-0.74) 
(Sarricolea and Martín-Vide, 2014), and very much lower than southern China (0.74-0.80) (Zhang et al., 2009; Fu et al., 2012). A recent study of precipitation concentration around the world, by Monjo and Martín-Vide (2016), found values from 0.38 to 0.87 for the entire land area, whereas Spain obtained a range of $0.66-0.87$. Although the concentration values were not according to the rest of the previous (or present) works (mainly due to the low spatial resolution), the comparison with the rest of the world in relative terms shows that the maximum concentration in Spain (in the eastern IP and Canary Islands) are comparable with the maximums in the Middle West, southern South America, or eastern continental Asia. Overall, the spatial pattern in the IP show the highest concentrations at orographic barriers near to the coast, and lowest values in inner continental lands flanked by mountains, is reproduced (with the exception of desert areas in Middle West) at a global scale, being very similar in South America, southern North America, Australia, Eurasia, and eastern Africa.

Most of the previous works of precipitation trends in Spain indicated a decrease in winter and spring precipitations and an increase in autumn (De Luis et al., 2010b; Rodríguez-Puebla et al., 2010; González-Hidalgo et al., 2011). These changes in the seasonality can be related with the widespread increasing pattern showed in CI trends, due to the decrease of precipitations in lower torrentiality periods and the increase when the extreme events are more frequent (FernándezMontes et al., 2014). However, the CI trends showed a high spatial variability that, considering that the CI is an index based on extreme precipitation, it can be highly influenced by local factors and by the irregular distribution in space and time of these high precipitation events (Merino et al., 2016). These situations can be reflected in the CI trends spatial distribution, showing isolated areas with different sign and magnitude that are mainly due to: i) the high spatial resolution of the gridded dataset and ii) the high number of stations used to build it. Both premises reflect the local character of precipitation at each individual point. The use of individual models for each location and day to estimate daily precipitation produces that the local effects, as orography or specific atmospheric situations (always depending on surrounding observations), have more influence in 
the precipitation estimation. The final data series for each point are more realistic and more influenced by extremes, which can change the sign and significance of trends in small areas.

These premises, related with the representativeness of the gridded dataset, can also explain that most of the highest significant trends coincides with high inter-annual irregularity (CIcv) areas (Figure 8). The spatial distribution of this relationship, that prevails in the eastern IP with some exceptions like the Central Range, and its potential causes, such as a warming of the water in the Mediterranean Basin and other atmospheric or geographical factors, will be investigated in further research.

\section{Conclusions}

This study of the daily precipitation concentration index (CI) in Spain gives, for the first time, a comprehensive description of its mean values, variability, extremes, and trends. The results are available due to the high spatial resolution of the climatic database and its creation based on more than 12,000 daily precipitation series. The maximum concentration values of precipitation in Spain are higher than those shown in previous studies, and they are mainly located in the eastern IP and in the Canary Islands. The study of trends showed a general significant increasing trend, intensified in those areas with higher inter-annual variability, and the presence of orographic barriers near to the coast are shown as a key factor to explain the spatial distribution of the highest concentration values. Spain is a heterogeneous area in respect of its precipitation distribution, regimes, trends, extreme events frequency, and its daily precipitation concentration. The increase in precipitation concentration from the mid-20 $0^{\text {th }}$ Century also means an increase in many environmental risks such as erosivity, floods, and extreme events, amongst others.

The CI index has a great potential to assess daily precipitation risks, and it is complementary to other indices such as the Precipitation Concentration Index (PCI) that evaluate the concentration at different scales. The results obtained from the application of CI are of key importance to regional planning and for decision-making policies related to environmental risks. 


\section{Acknowledgements}

This study was supported by research projects CGL2015-69985-R and CGL2014-52135-C3-1-R, and financed by the Spanish Ministerio de Economía y Competitividad (MINECO) and EU FEDER-ERDF funds. RSN, MDL, MAS, and LAL were supported by the Government of Aragón through the 'Programme of research groups' (group H38, 'Clima, Agua, Cambio Global y Sistemas Naturales’), as well as SB (group 'E68, Geomorfología y Cambio Global’). The authors would also like to thank the Climatology Group (2014SGR300, Catalan Government), the Convenio de Desempeño UTA-MINEDUC, and the FONDECYT Project 11160059 of the Chilean Government.

\section{References}

Alijani B, O’Brien J, Yarnal B. 2008. Spatial analysis of precipitation intensity and concentration in Iran. Theor. Appl. Climatol. 94: 107-124. https://doi.org/10.1007/s00704-0070344-y.

Álvarez E, Espejo F, Cortés F J, Lafragüeta C, Serrano-Notivoli R. 2011. Caracterización sinóptica de los procesos convectivos en el interior del nordeste peninsular, Aemet, Madrid.

Benhamrouche A, Boucherf D, Hamadache R, Bendahmane L, Martin-Vide J, Teixeira Nery J. 2015. Spatial distribution of the daily precipitation concentration index in Algeria. Nat. Hazards Earth Syst. Sci. 15: 617-625. https://doi.org/10.5194/nhess-15-617-2015.

Benhamrouche A, Martín-Vide J. 2012. Avances metodológicos en el análisis de la concentración diaria de la precipitación en la España peninsular. Anales de Geografía de la Universidad Complutense 32(1): 11-27. https://doi.org/10.1007/s11069-013-1015-1 10.5209/rev_AGUC.2012.v32.n1.39306.

Bladé I, Castro-Díez Y. 2010. Atmospheric trends in the Iberian Peninsula during the instrumental period in the context of natural variability. In: CLIVAR-Spain Report 2010. Climate in Spain: Past, present and future. Regional climate change assessment report. Editors: Pérez FF, Boscolo R. Available online in: http://clivar.es/wp-content/uploads/2015/06/CLIMATE-IN-SPAIN-PastPresent-and-Future.-Regional-climate-change-assessment-report-2010.pdf

Caloiero T. 2014. Analysis of daily rainfall concentration in New Zealand. Nat. Haz. 72: 389404. https://doi.org/10.1007/s11069-013-1015-1.

Cortesi N, González-Hidalgo J C, Brunetti M, Martín-Vide J. 2012. Daily precipitation concentration across Europe 1971-2010. Nat. Hazards Earth Syst. Sci. 12: 2799-2810. https://doi.org/10.5194/nhess-12-2799-2012.

Cortesi N, González-Hidalgo J, Brunetti M, De Luis, M. 2014. Spatial variability of precipitation in Spain. Reg. Env. Change 14(5): 1743-1749. https://doi.org/10.1007/s10113-012-0402-6.

Coscarelli R, Caloiero T. 2012. Analysis of daily and monthly rainfall concentration in Southern Italy (Calabria region). J. Hydrol. 416-417: 145-156. https://doi.org/10.1016/j.jhydrol.2011.11.047.

De Luis M, González-Hidalgo JC, Longares LA. 2010a. Is the rainfall erosivity increasing the Mediterranean Iberian Peninsula? Land Degrad. Dev. 21: 139-144. https://doi.org/10.1002/ldr.918. 
De Luis M, Brunetti M, González-Hidalgo JC, Longares LA, Martín-Vide J. 2010b. Changes in seasonal precipitation in the Iberian Peninsula during 1946-2005. Global Planet. Change. 74: 27-33. https://doi.org/10.1016/j.gloplacha.2010.06.006.

De Luis M, González-Hidalgo JC, Brunetti M, Longares LA. 2011. Precipitation concentration changes in Spain 1946-2005. Nat. Hazards Earth Syst. Sci. 11: 1259-1265. http://doi.org/10.5194/nhess-11-1259-2011.

Esteban-Parra MJ, Rodrigo FS, Castro-Díez Y. 1998. Spatial and temporal patterns of precipitation in Spain for the period 1880-1992. Int. J. Climatol. 18: 1557- 1574. http://doi.org/10.1002/(SICI)1097-0088(19981130)18:14\%3C1557::AIDJOC328\%3E3.3.CO;2-A.

Fernández-Montes S, Seubert S, Rodrigo FS, Rasilla Álvarez DF, Hertig E, Esteban P, Philipp A. 2014. Circulation types and extreme precip-itation days in the Iberian Peninsula in the transition seasons: spatial links and temporal changes. Atmos. Res. 138: 41-58. https://doi.org/10.1016/j.atmosres.2013.10.018.

Fu H, Luo Y, Wang W, Jiang Y, Xiong Y. 2012. Analysis of precipitation concentration in Gaoyou Irrigation District: implications for increasing effective rainfall. Appl. Mech. Mater. 212213: 311-315. http://doi.org/10.4028/www.scientific.net/AMM.212-213.311.

García-Barrón L, Aguilar M, Sousa A. 2011. Evolution of annual rainfall irregularity in the southwest of the Iberian Peninsula. Theor. Appl. Climatol. 103: 13-26. http://doi.org/10.1007/s00704-010-0280-0.

González-Hidalgo J, Brunetti M, De Luis M. 2011. A new tool for monthly precipitation analysis in Spain: MOPREDAS database (monthly precipitation trends December 1945-November 2005) Int. J. Climatol. 31(5): 715- 731. http://doi.org/10.1002/joc.2115.

Haylock MR, Hofstra N, Klein Tank AMG, Klok EJ, Jones PD, New M. 2008. A European daily high-resolution gridded dataset of surface temperature and precipitation. J. Geophys. Res (Atmospheres), 113, D20119. http://doi.org/10.1029/2008JD010201.

Herrera S., Fernández J., Gutiérrez J.M. 2016. Update of the Spain02 Gridded Observational Dataset for Euro- CORDEX evaluation: Assessing the Effect of the Interpolation Methodology, Int. J. Climatol., 36: 900-908. http://doi.org/10.1002/joc.4391.

Harris I, Jones PD, Osborn TJ, Lister DH. 2014. Updated high-resolution grids of monthly climatic observations - the CRU TS3.10 Dataset. Int. J. Climatol. 34 (3): 623-642. http://doi.org/10.1002/joc.3711.

Huffman GJ, Adler RF, Arkin P, Chang A, Ferraro R, Gruber A, Janowiak J, McNab A, Rudolf B, Schneider U. 1997. The Global Precipitation Climatology Project (GPCP) Combined Precipitation Dataset. Bull. Am. Meteorol. Soc. 78 (1): 5-20. http://doi.org/10.1175/15200477(1997)078\%3C0005:TGPCPG\%3E2.0.CO;2

Kendall MG. 1948. Rank correlation methods. Charles Griffin, Oxford.

Mann HB. 1945. Nonparametric tests against trend. Econometrica 13 (3): 245-259. http://doi.org/10.2307/1907187.

Martín-Vide J. 2004. Spatial distribution of a daily precipitation concentration index in peninsular Spain. Int. J. Climatol. 24 (8): 959-971. http://doi.org/10.1002/joc.1030.

Martín-Vide J, López-Bustins JA. 2006. The western Mediterranean oscillation and rainfall in the Iberian Peninsula. Int. J. Climatol. 26: 1455-1475. http://doi.org/10.1002/joc.1388.

Máyer P, Marzol MV. 2014. Daily precipitation concentration and the rainy spells in the Canary Islands: two risk factors. Boletín de la Asociación de Geógrafos Españoles. 65: 463-468.

Merino A, Fernández-Vaquero M, López L, Fernández-González S, Hermida L, Sánchez JL, García-Ortega E, Gascón E. 2016. Large-scale patterns of daily precipitation extremes on the Iberian Peninsula. Int. J. Climatol. 36 (11): 3873-3891. http://doi.org/10.1002/joc.4601.

Meseguer-Ruiz O, Martín-Vide J, Olcina-Cantos J, Sarricolea P. 2014. The spatial distribution of the temporal fractality of precipitation in peninsular Spain and its relationship with the concentration index. Investig. Geogr. Chile 48: 73-84. http://doi.org/10.5354/07195370.2014.36677. 
Monjo R, Martin-Vide J. 2016. Daily precipitation concentration around the world according to several indices. Int. J. Climatol. 36 (11): 3828-3838. http://doi.org/10.1002/joc.4596.

Quintana-Seguí P, Turco M, Herrera S, Miguez-Macho G. 2017. Validation of a new SAFRANbased gridded precipitation product for Spain and comparison to Spain02 and ERA-Interim. Hydrol. Earth Syst. Sci. 21: 2187-2201, http://doi.org/10.5194/hess-21-2187-2017.

Rodríguez-Puebla C, Encinas AH, Nieto S, Garmendia J. 1998. Spatial and temporal patterns of annual precipitation variability over the Iberian Peninsula. Int. J. Climatol. 18: 299-316. http://doi.org/ 10.1002/(SICI)1097-0088(19980315)18:3<299::AID-JOC247>3.0.CO;2-L.

Rodríguez-Puebla C, Nieto S. 2010. Trends of precipitation over the Iberian Peninsula and the North Atlantic Oscillation under climate change conditions. Int. J. Climatol. 30: 1807-1815. http://doi.org/10.1002/joc.2035.

Sarricolea P, Martín-Vide J. 2014. Spatial analysis of rainfall daily trends and concentration in Chile. Investig. Geogr. Chile 47: 53-66. http://doi.org/10.5354/0719-5370.2014.32995.

Sen PK. 1968. Estimates of the regression coefficient based on Kendall's tau. J. Am. Stat. Assoc. 63 (324): 1379-1389. http://doi.org/10.2307/2285891.

Serrano-Notivoli R, Beguería S, Saz MA, Longares LA, De Luis M. 2017a. SPREAD: A highresolution daily gridded precipitation dataset for Spain. An extreme events frequency and intensity overview. Earth Syst. Sci. Data. 9: 721-738. https://doi.org/10.5194/essd-9-721-2017.

Serrano-Notivoli R, De Luis M, Beguería S. 2017b. An R package for daily precipitation climate series reconstruction. Environ. Modell. Soft. 89: 190-195. https://doi.org/10.1016/j.envsoft.2016.11.005

Serrano-Notivoli R, De Luis M, Saz MA, Beguería S. 2017c. Spatially-based reconstruction of daily precipitation instrumental data series. Clim. Res. 73 (3), 167-184. https://doi.org/10.3354/cr01476.

Shi P, Wu M, Qu S, Jiang P, Quiao X, Chen X, Zhou M, Zhang Z. 2015. Spatial Distribution and Temporal Trends in Precipitation Concentration Indices for the Southwest China. Water Resour. Manag. 29: 3941-3955. https://doi.org/10.1007/s11269-015-1038-3.

Suhaila J, Jemain AA. 2012. Spatial analysis of daily rainfall intensity and concentration index in Peninsular Malaysia. Theor. Appl. Climatol. 108: 235-245. https://doi.org/10.1007/s00704-0110529-2.

Venezian L, Teixeira J. 2016. precintcon: Precipitation Intensity, Concentration and Anomaly Analysis. R package version 2.3.0. https://CRAN.R-project.org/package=precintcon (accessed 31.05.17).

Vicente-Serrano SM, López-Moreno JI, Beguería S, Lorenzo-Lacruz J, Sánchez-Lorenzo A, García-Ruiz JM, Azorín-Molina E, Morán-Tejeda E, Revuelto J, Trigo R, Coelho F, Espejo F. 2014. Evidence of increasing drought severity caused by temperature rise in southern Europe. Environ. Res. Letters 9(4): 44001. https://doi.org/10.1088/1748-9326/9/4/044001.

Vicente-Serrano SM, Azorin-Molina C, Sanchez-Lorenzo A, El Kenawy A, Martín-Hernández N, Peña-Gallardo M, Beguería S, Tomas-Burguera M. 2016. Recent changes and drivers of the atmospheric evaporative demand in the Canary Islands. Hydrol. Earth Syst. Sc. 20(8): 3393-3410. https://doi.org/10.5194/hess-20-3393-2016.

Zhang Q, Xu C Y, Marco G, Chen YP, Liu CL. 2009. Changing properties of precipitation concentration in the Pearl River basin, China. Stoch. Env. Res. Risk. Assess. 23: 377-385. https://doi.org/10.1007/s00477-008-0225-7.

Zubieta R, Saavedra M, Silva Y, Giráldez L. 2016. Spatial analysis and temporal trends of daily precipitation concentration in the Mantaro River basin: central Andes of Peru. Stoch. Environ. Res. Risk. Assess. 31: 1305. https://doi.org/10.1007/s00477-016-1235-5. 


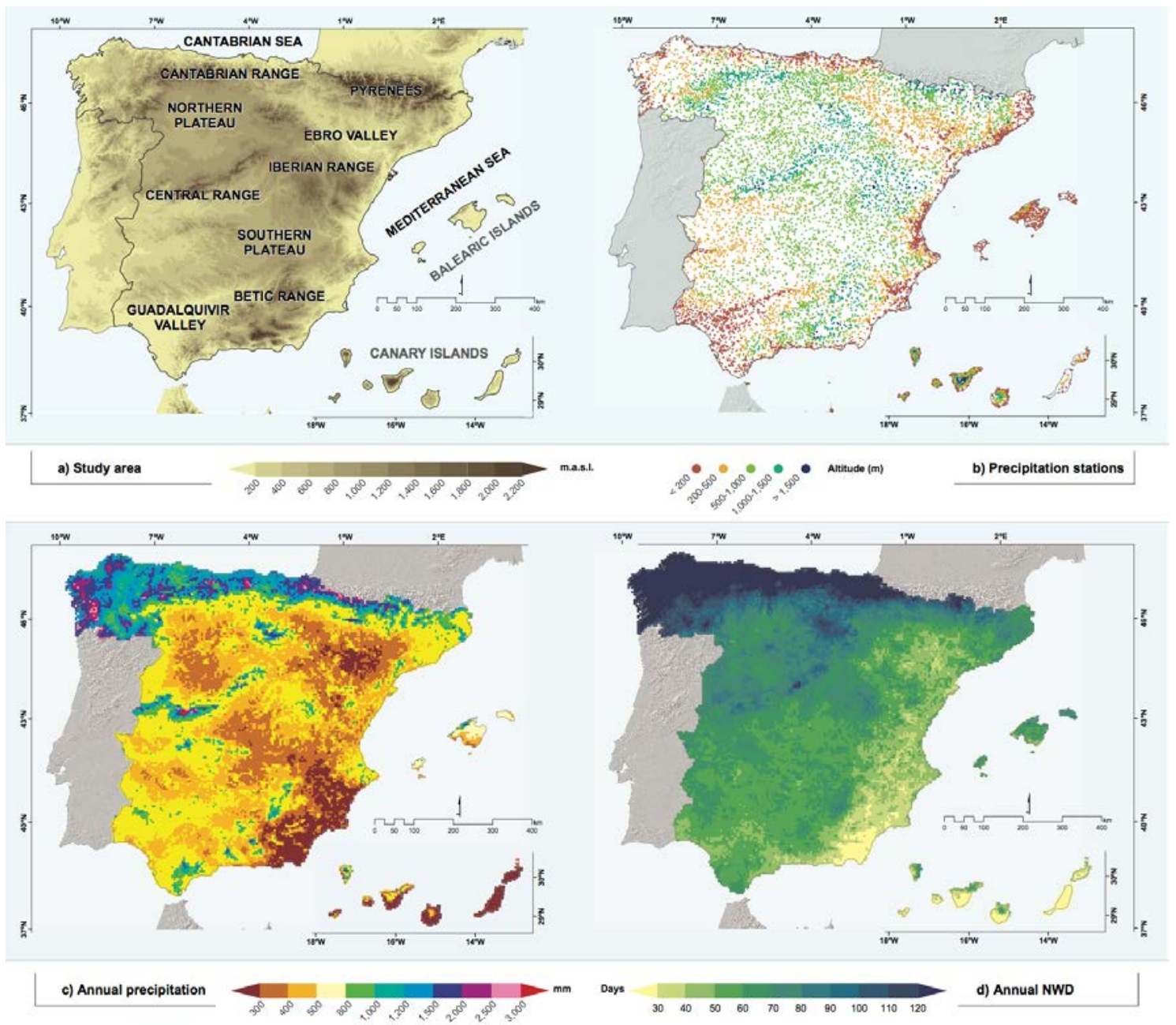

Figure 1. (a) Geographical references of the study area; (b) location of the observatories used to build the gridded data set; (c) average annual precipitation (1950-2012), and (d) average number of wet (precipitation>0 mm) days (NWD) (1950-2012). 

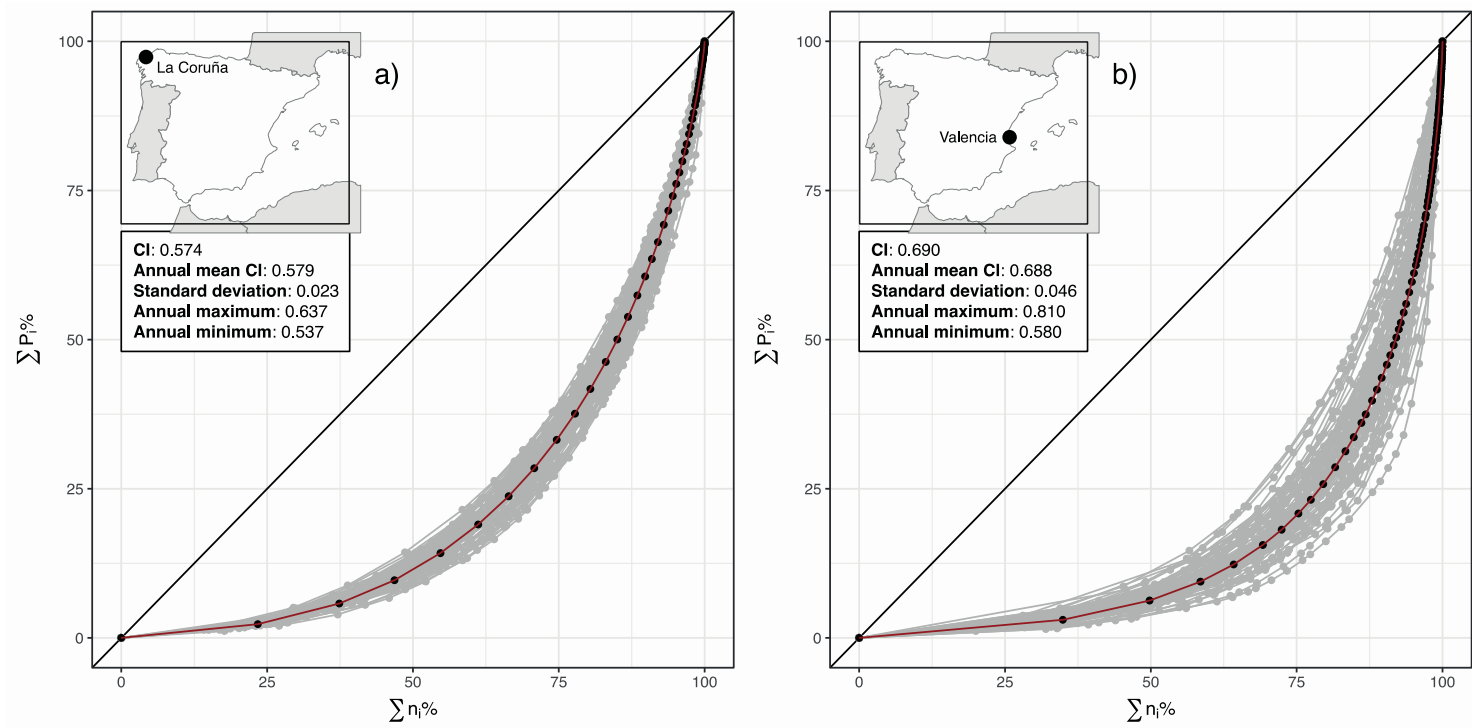

Figure 2. Cumulative percentage of rainy days ( $\sum$ ni $\left.\%\right)$ versus the cumulative percentage of rainfall amounts $\left(\sum \mathrm{Pi} \%\right)$ in (a) La Coruña and (b) Valencia. Black dots with red lines are the exponential curves using complete series, and grey dots and lines are the annual exponential curves. 


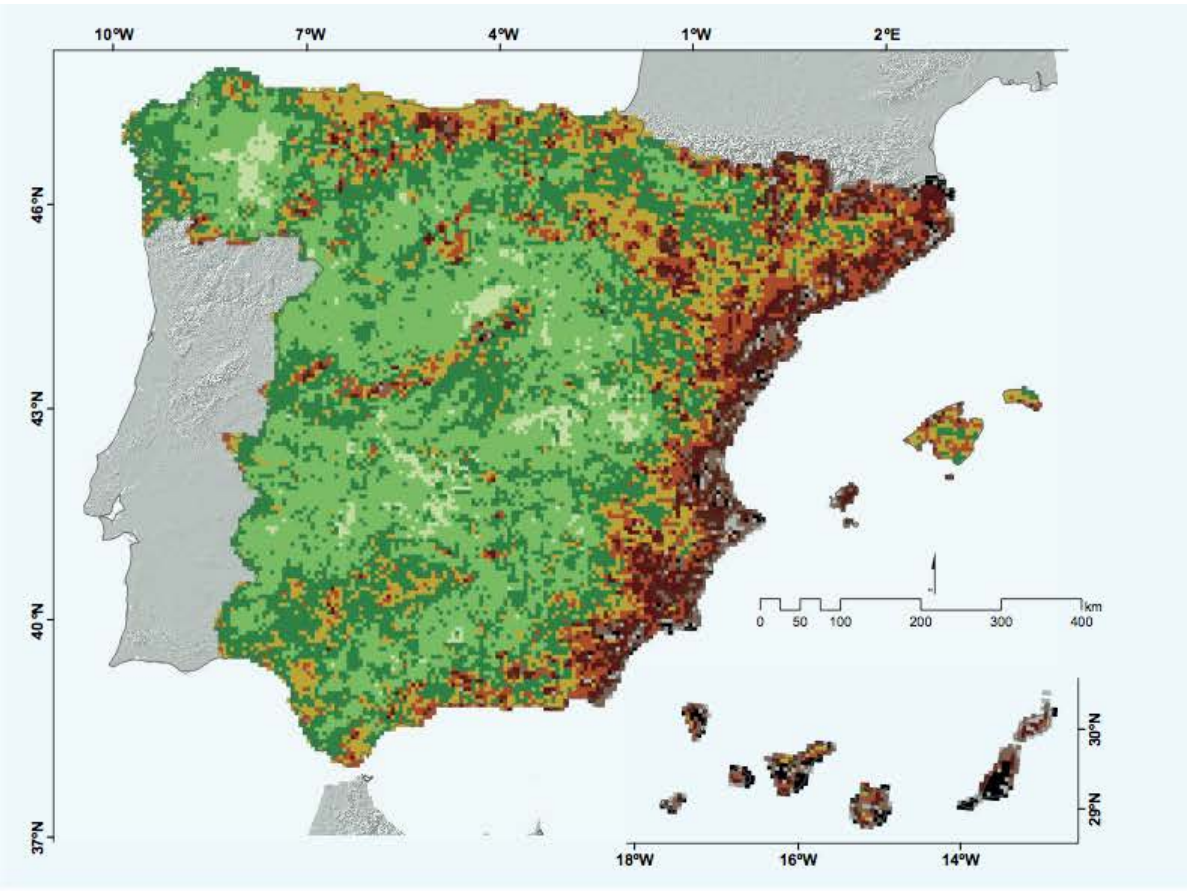

a) Complete series

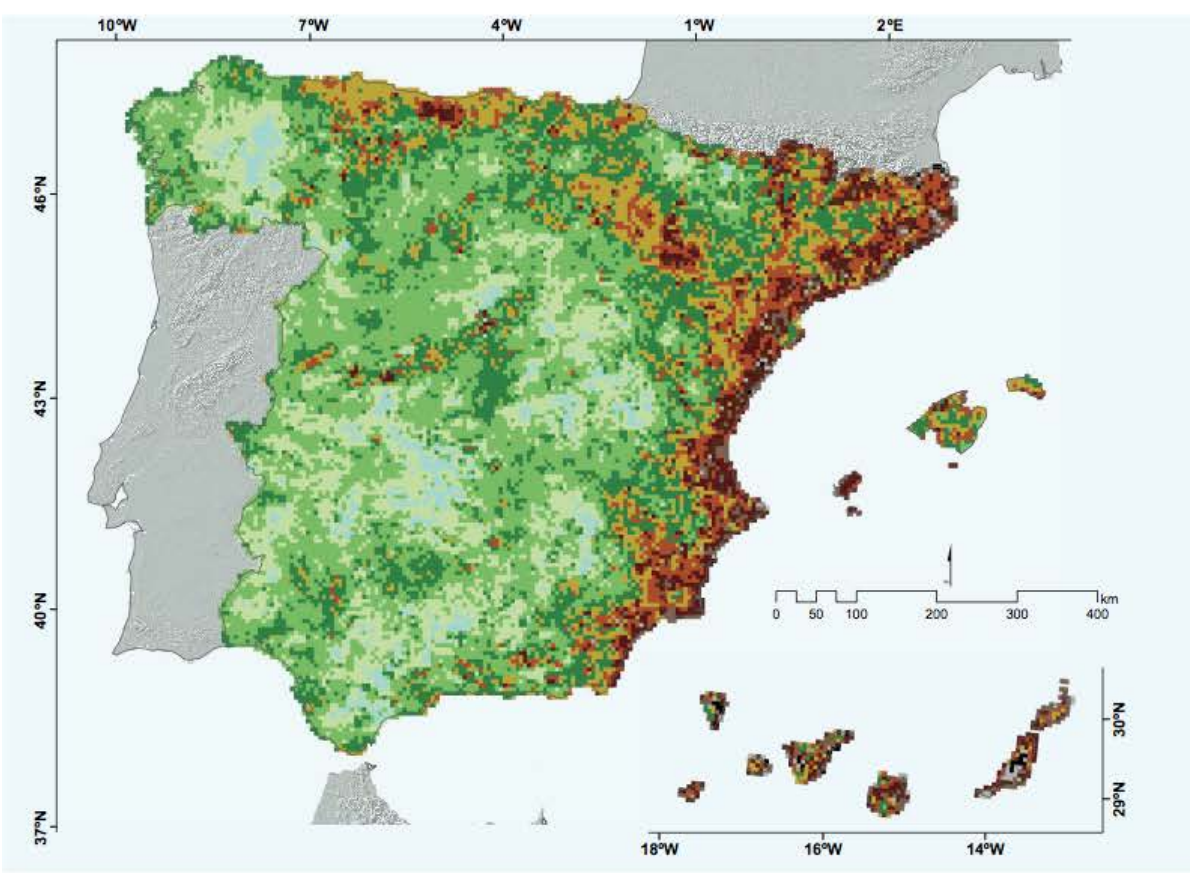

b) Annual mean series

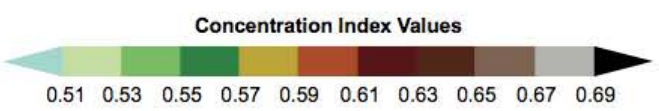

Figure 3. PCI in peninsular Spain (1950-2012), and the Balearic and Canary Islands (1971-2012) using (a) complete series (CIc) and (b) mean annual series (CIm). 

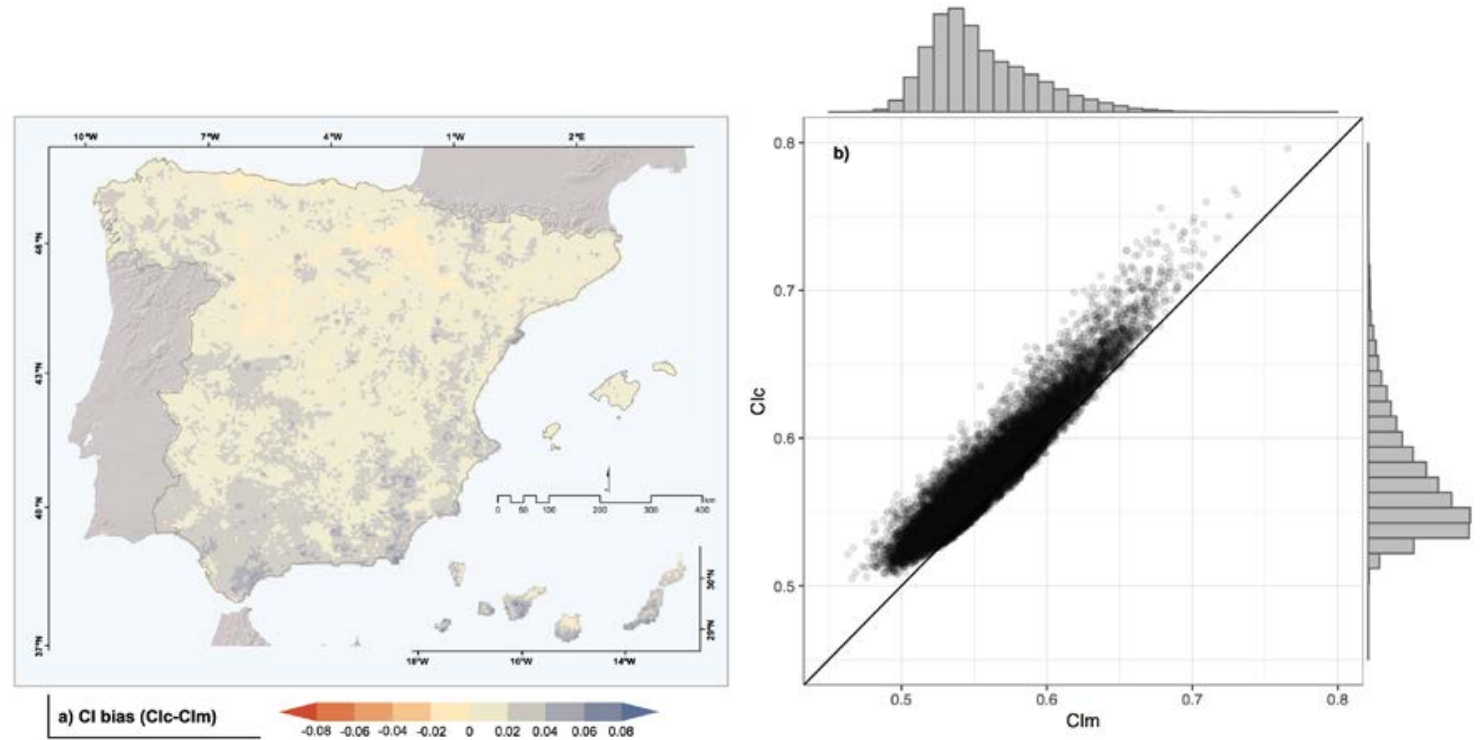

Figure 4. (a) CI bias (CIc-CIm) spatial distribution and (b) scatterplot of averaged annual CI values (CIm) versus the CI computed with complete series (CIc). Dots represent the grid points covering Spain, the black line shows the optimal t where both variables give the same values, and histograms show the frequencies of values. 


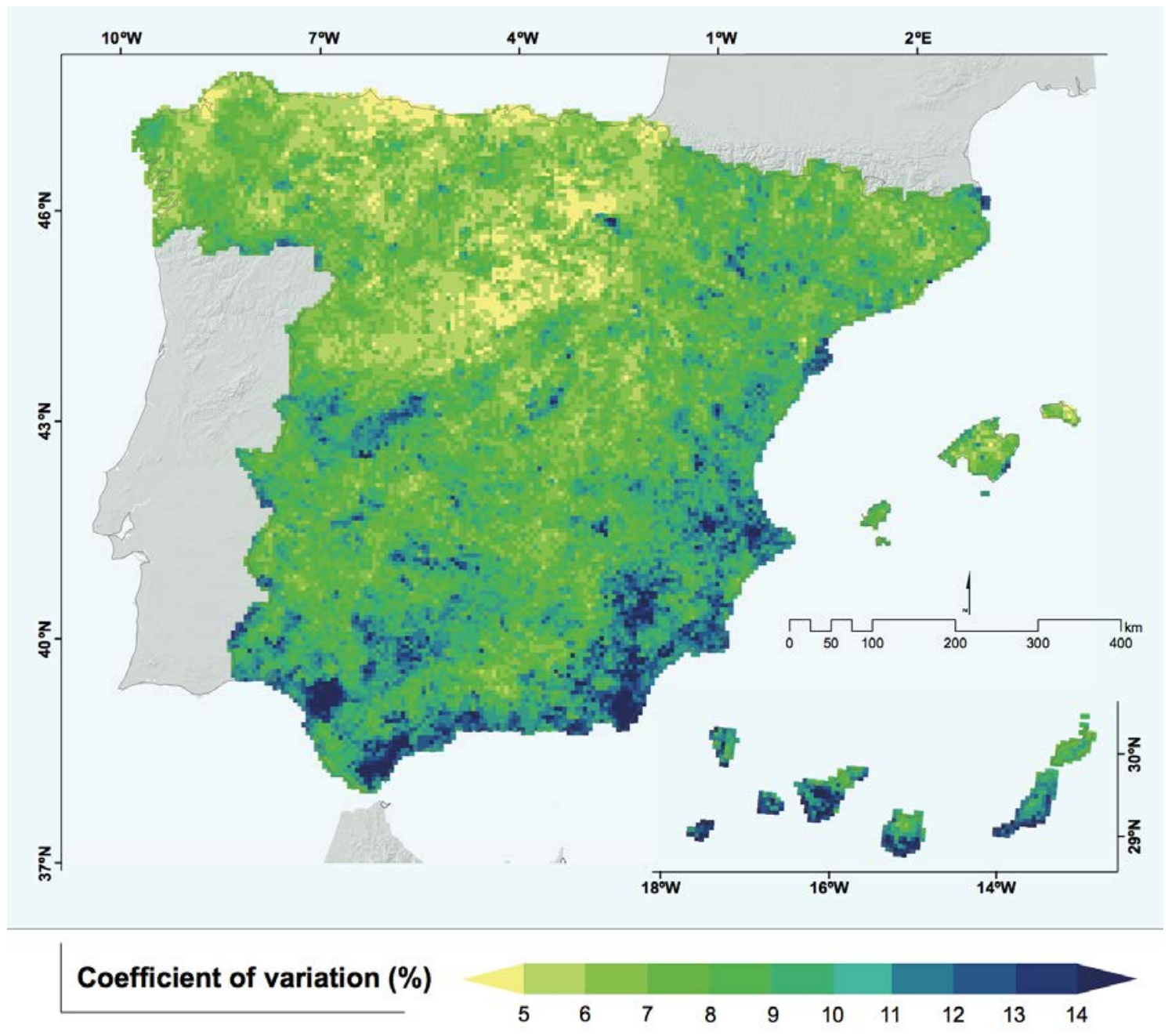

Figure 5. Coefficient of variation of annual CI values (CIcv). 


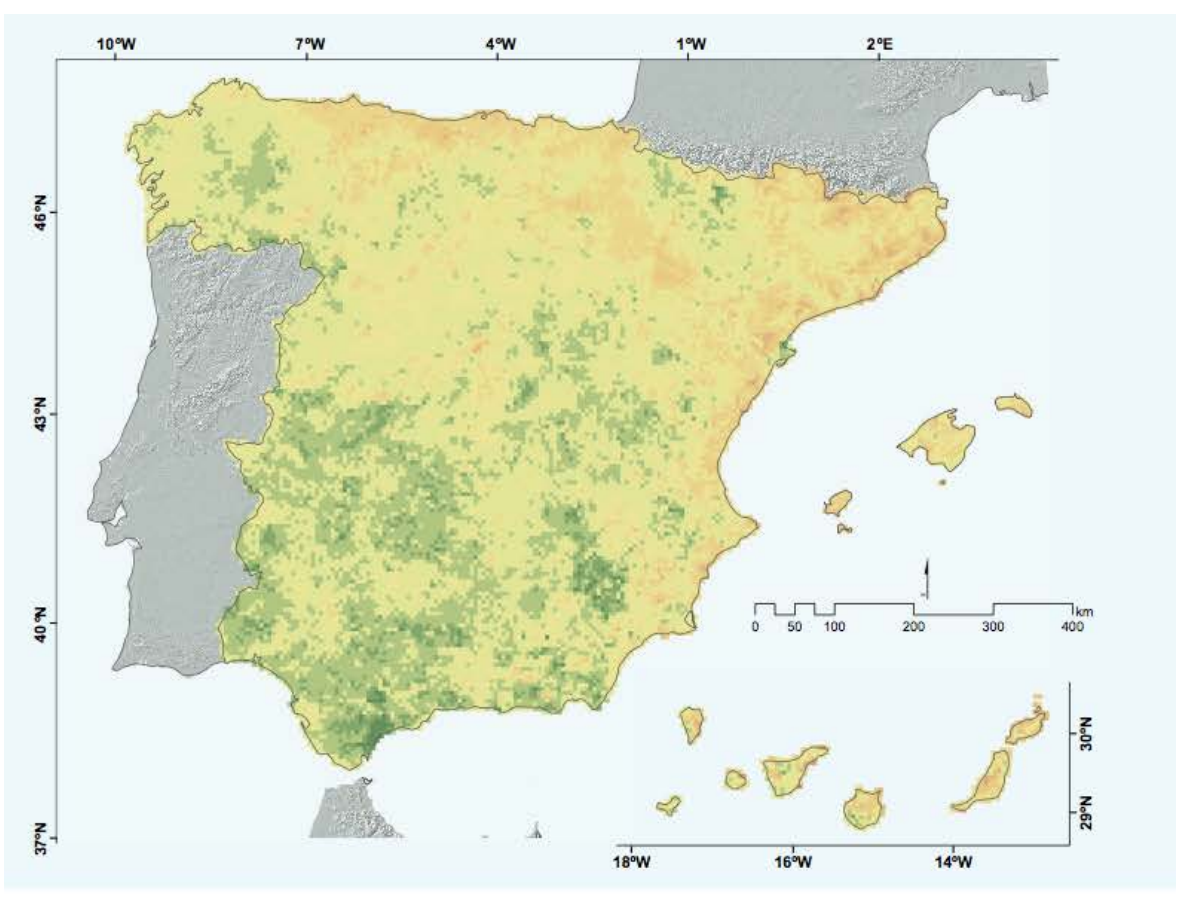

a) $5^{\text {th }}$ percentile

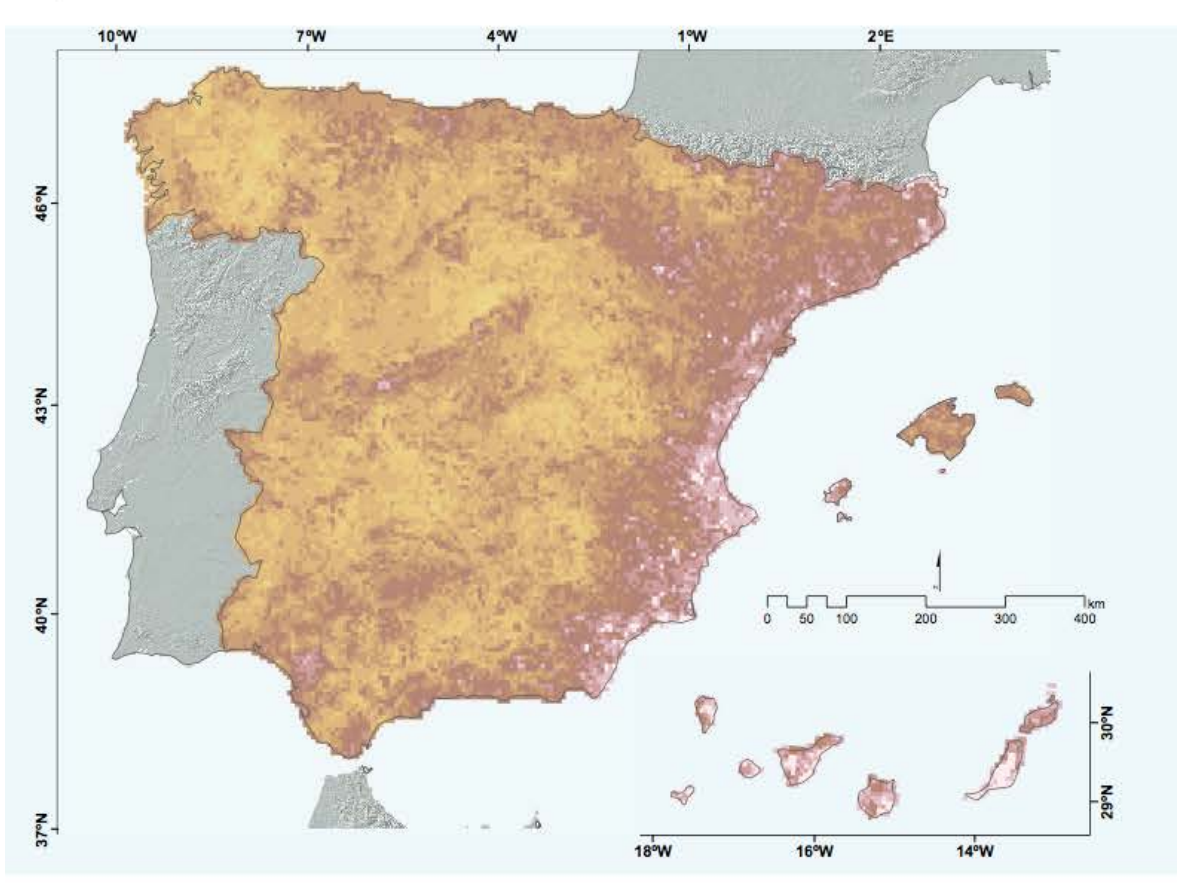

b) $95^{\text {th }}$ percentile

Concentration Index Values

$\begin{array}{lllllllllllll}0.40 & 0.43 & 0.46 & 0.49 & 0.52 & 0.55 & 0.58 & 0.61 & 0.64 & 0.67 & 0.70 & 0.73 & 0.76\end{array}$

Figure 6. (a) Fifth and (b) 95th percentile of annual CI values. 


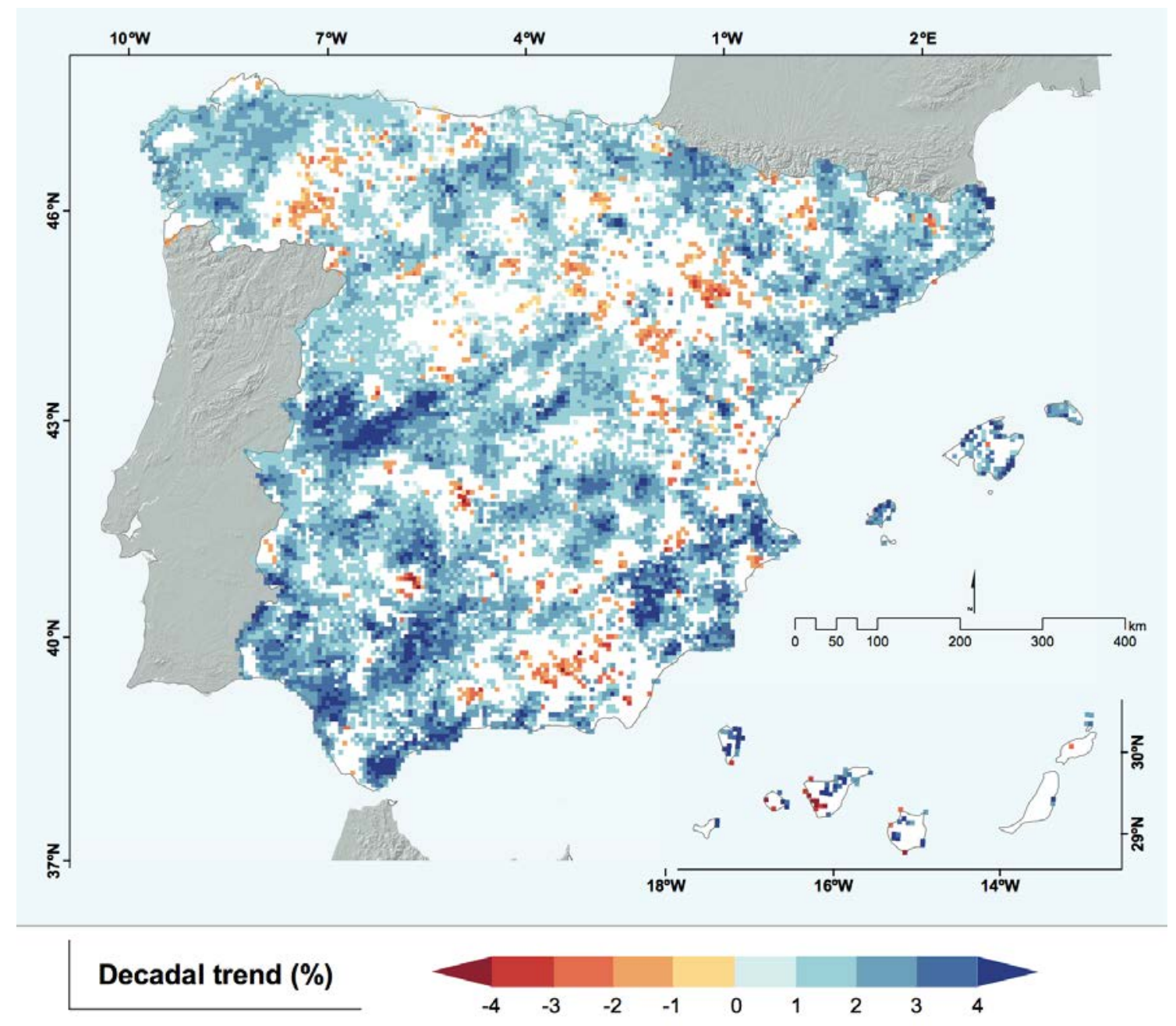

Figure 7. Percentage of change by decade of annual CI in Spain (1950 - 2012). Only significant trends $(p<0.05)$ are represented in colour, while non-significant areas are left white. 


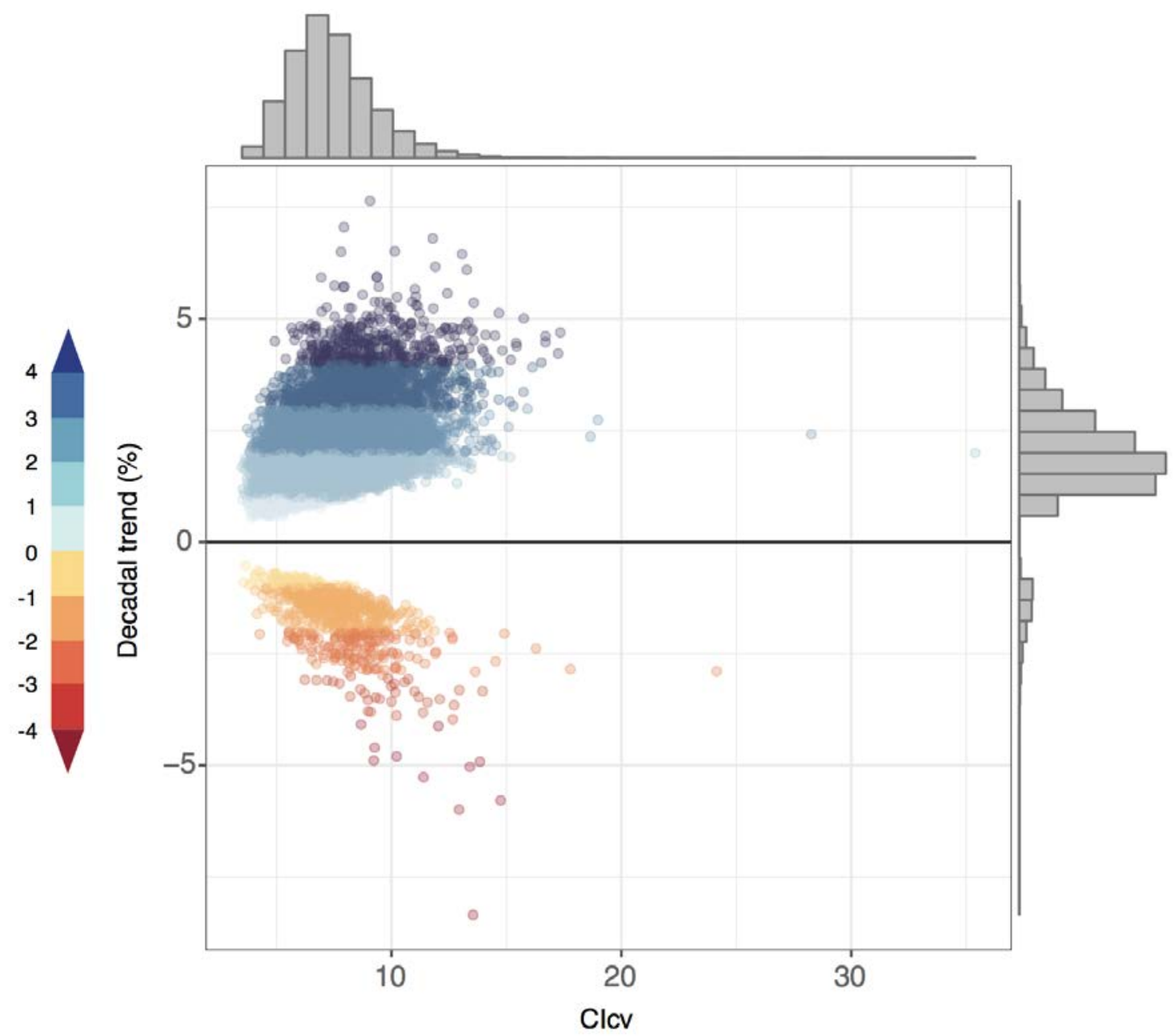

Figure 8. Scatterplot of the coef cient of variation computed from the detrended time series of annual CI versus the CI signi cant decadal trends. Dots represent the grid points covering Spain, colours indicate the trend magnitude, and histograms show the frequencies of values. 